\title{
Does Nissen fundoplication improve deglutition in children?
}

\author{
Tutku Soyer ${ }^{1}$, Şule Yalçın ${ }^{1}$, Numan Demir ${ }^{2}$, Asuman Nur Karhan ${ }^{3}$, İnci Nur Saltık- \\ Temizel $^{3}$, Hülya Demir ${ }^{3}$, Feridun Cahit Tanyel ${ }^{1}$ \\ ${ }^{1}$ Departments of Pediatric Surgery and ${ }^{3}$ Pediatric Gastroenterology, Hepatology and Nutrition, Hacettepe University Faculty \\ of Medicine, ${ }^{2}$ Department of Physiotherapy and Rehabilitation, Hacettepe University, Faculty of Health Sciences, Ankara, \\ Turkey.E-mail: soyer.tutku@gmail.com \\ Received: 4th November 2016, Revised: 13th January 2017, Accepted: 25th January 2017
}

SUMMARY: Soyer T, Yalçın S, Demir N, Karhan AN, Saltık-Temizel İN, Demir $\mathrm{H}$, Tanyel FC. Does Nissen fundoplication improve deglutition in children? Turk J Pediatr 2017; 59: 28-34.

A prospective study was performed to evaluate the effect of Nissen fundoplication (NF) on deglutition in children. Children who underwent NF between 2011-2015 were evaluated for demographic features, clinical findings, diagnostic methods for gastroesophageal reflux (GER) and indications for NF. Penetration aspiration scale (PAS), functional oral intake scale (FOIS) and esophageal functions were evaluated by videoflouroscopy (VFS). Preoperative and postoperative VFS findings were compared to evaluate the effect of NF on clinical findings and deglutition. Twenty-three children with a mean age of 5.08 \pm 3.7 years were included. Female to male ratio was 15:8. Recurrent respiratory infections (RTI) (n: 14, 60.8\%), swallowing dysfunction (n:13, 56.5\%) and vomiting (n:10, 43.4\%) were the most common symptoms. Preoperatively GER was diagnosed with barium swallowing study (BSS) contrast graphs (n:20, $87 \%$ ) and with 24-hour esophageal $\mathrm{pH}$ monitorization ( $\mathrm{n}: 8,34.8 \%$ ). In $39.1 \%$ of patients, medical treatment for GER was used with a mean duration of 8 \pm 5.8 months. Indications for NF were swallowing dysfunction (n: 18, 78\%), GER complications ( $\mathrm{n}: 6,26 \%$ ), associated anatomical problems (n:4, 17.3\%) and unresponsiveness to medical treatment (n: 3, 13\%). Postoperative barium swallowing study and 24-hour esophageal $\mathrm{pH}$ monitorization showed no GER after NF in $95 \%$ of patients. Number of RTI were significantly decreased after NF (preoperative vs postoperative infection rate 4.21 vs 1.6 respectively, $\mathrm{p}<0.05)$. VFS findings showed that PAS was significantly decreased after NF during both liquid and semi-liquid swallowing $(\mathrm{p}<0.05)$. After NF, upper esophageal opening (UEO) was decreased when compared to preoperative VFS findings $(\mathrm{p}<0.05$ Esophageal cleaning, esophageal motility, esophageal backflow and lower esophageal sphincter narrowing did not alter after NF $(p>0.05)$. FOIS were significantly improved after NF $(p<0.05)$. VFS findings showed that penetration and aspiration were significantly decreased after NF and children had less RTI. Although, esophageal motility evaluated by VFS did not changed after NF, functional oral intake significantly improved in children.

Key words: Nissen fundoplication, gastroesophageal reflux, deglutition, dysphagia.

Nissen fundoplication (NF) is a common surgical procedure in children with gastroesophageal reflux disease (GERD) and swallowing dysfunction. Dysphagia is a common complication of antireflux surgery in the early postoperative period resulting from tight or twisted fundoplication, paraesophegal herniation and hiatal stenosis ${ }^{1}$. Although, several studies have evaluated the effect of NF on esophageal motility, none of the symptom associated indices and motility studies prior to surgery are able to predict the post-operative improvement or complications ${ }^{2}$. Myers et $\mathrm{al}^{3}$. adopted a new dysphagia score to evaluate pharyngeal bolus clearance and aspiration risk after fundoplication ${ }^{3}$. Although this is a 
highly sensitive method to predict postoperative dysphagia, it requires manometric intervention.

Videofluoroscopy (VFS) is a dynamic method investigating oral, pharyngeal and esophageal phases of swallowing in children. It is easy to perform and well tolerated by children. In addition to physiologic phases of deglutition, VFS gives an idea about aspiration and bolus passage of food along the esophageal body during the examination. In order to evaluate the effects of NF on deglutitive functions, preoperative and postoperative swallowing functions of children were investigated by VFS. In addition to VFS findings, penetration aspiration (PAS) and functional oral intake scales (FOIS) were compared before and after antireflux surgery ${ }^{4}$.

\section{Material and Methods}

Children who underwent NF between 20112015 were evaluated for demographic features, clinical findings, diagnostic methods for gastroesophageal reflux (GER) and indications for NF, retrospectively. Patients who had VFS before and after NF were included. Children with esophageal stricture were excluded from the study. Penetration aspiration scale (PAS), functional oral intake scale (FOIS) and esophageal functions were evaluated by videoflouroscopy (VFS). Parameters of VFS, PAS and FOIS are shown in Tables I to III, respectively.

Surgical technique of NF includes dividing short gastric vessels and performing a $2-3 \mathrm{~cm}$ floppy wrap over 30-48 Fr bougie. Hiatal closure was performed in patients with wide hiatal opening. Postoperative evaluations including upper GI studies, pH metry and VFS were performed 3 months after fundoplication. PAS and FOIS scales were also evaluated 3 months after surgery. The results of preoperative and postoperative VFS, PAS and FOIS findings were compared to evaluate the effect of NF on clinical findings and deglutition.

\section{Videofluoroscopic evaluation}

Table I. Parameters of Videoflouroscopy.

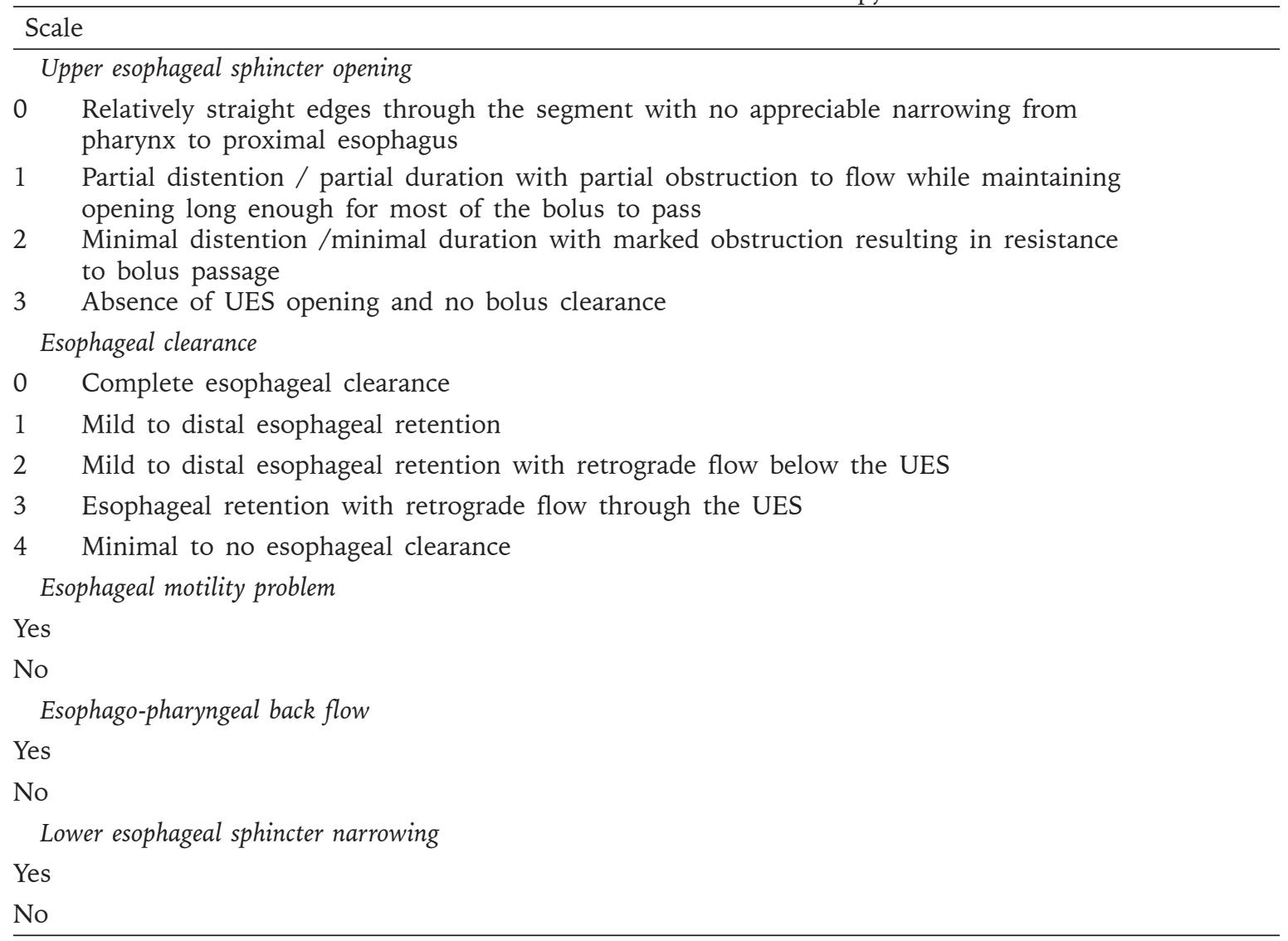

UES: Upper esophageal sphincter 

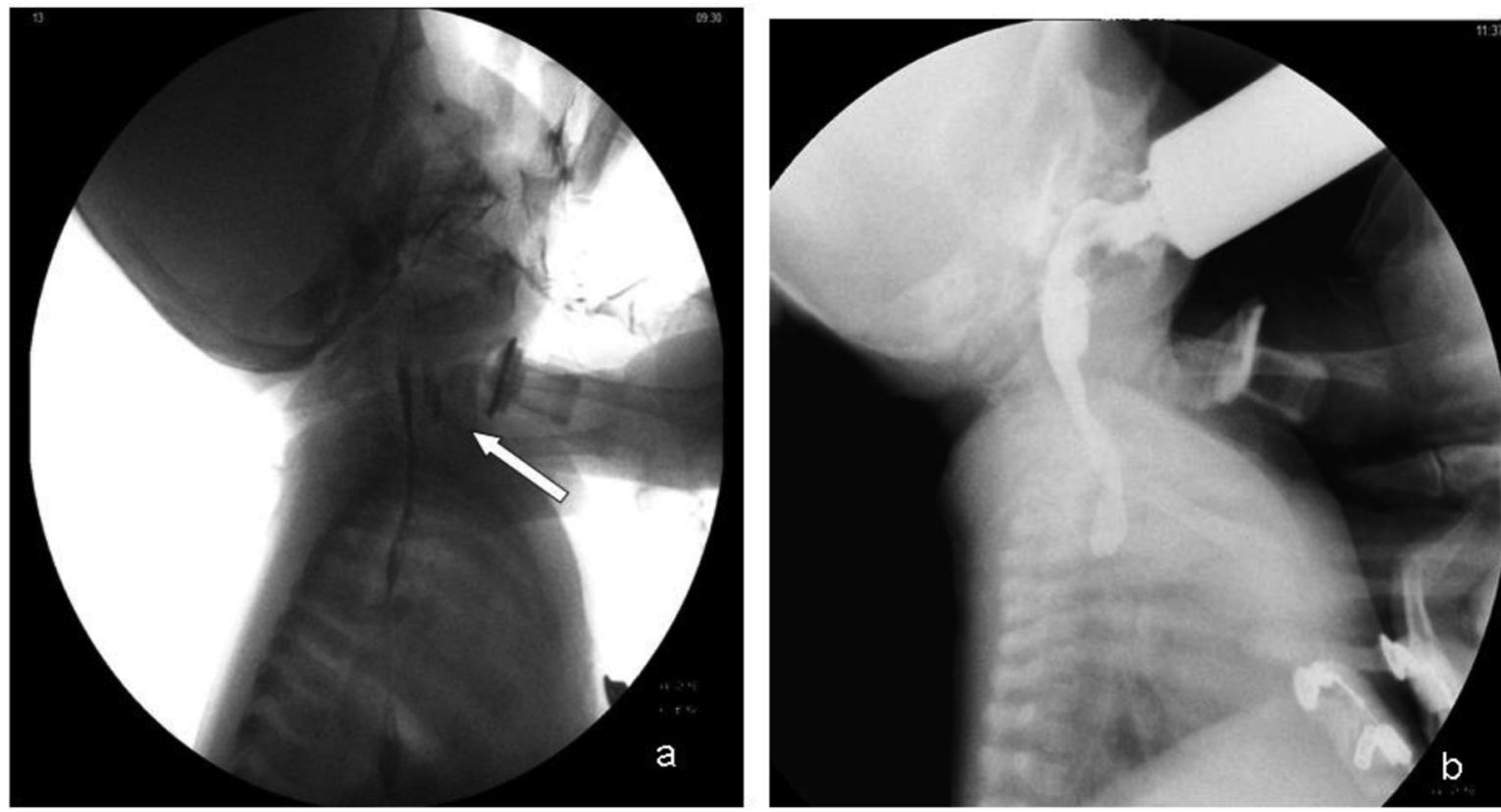

Fig. 1. Aspiration of liquids in preoperative videofluoroscopy (a) and improved after Nissen fundoplication (b).

Videofluoroscopy is known to be the basic method for the investigation of the deglutitive functions. Oral, pharyngeal and esophageal phases of deglutition are evaluated with different consistencies of food in this procedure $^{4}$. We performed liquid (1-3-5-10-20 $\mathrm{ml}$ of barium), pudding (3-5-10 $\mathrm{ml}$ of barium with pudding) and solid (5-10 $\mathrm{ml}$ of barium with biscuit) barium tests, and used the 5 $\mathrm{ml}$ volume results for the analysis, since this amount provides more effective evaluation of swallowing physiology. The parameters for the three phases of deglutition were analyzed and scored with a 0-3 point scale (Table I).

The penetration-aspiration scale (PAS) was also used in the evaluation of VFS findings, and the score of 1-2 defined 'no penetration and aspiration', 3-6 'penetration', and 7-8 'aspiration' (Table II) ${ }^{4}$.

\section{Evaluation of FOIS}

The FOIS pediatric scale was adopted by Crary and collugues form an existing adult tool ${ }^{5}$. It is a 7-point ordinal scale that documents the functional intake of food and liquid in patients (Table III) ${ }^{5}$.

\section{Statistical Analysis and Ethics}

The results were analyzed with SPSS 15.0. Non parametric two-related sampled test were used to compare the preoperative and postoperative

Table II. Parameters of Penetration Aspiration Scale.

\begin{tabular}{lll}
\hline Scale & & \\
\hline 1 & & No contrast in the airway \\
2 & No penetration and aspiration & Contrast at the supraglottic level, no contrast residue \\
3 & Penetration & $\begin{array}{l}\text { Contrast at the supraglottic level, visible contrast residue } \\
\text { Contrast at the level of glottis, no contrast residue }\end{array}$ \\
5 & Contrast at the level of glottis, visible contrast residue \\
6 & Contrast at the subglottic level, no contrast residue \\
7 & Aspiration & $\begin{array}{l}\text { Contrast at the subglottic level, visible contrast residue despite } \\
\text { the response of the patient } \\
\text { Contrast at the subglottic level, visible contrast residue with no } \\
\text { response of the patient }\end{array}$ \\
\hline
\end{tabular}


Table III. Parameters of Functional Oral Intake Scale.

\begin{tabular}{ll}
\hline Scale & \\
\hline 1 & No oral intake \\
2 & Tube dependence with minimal /inconsistent oral intake \\
3 & Tube supplements with consistent oral intake \\
4 & Total intake of a single consistency \\
5 & Total oral intake of multiple consistencies requiring special preparation \\
6 & Total oral intake with no special preparation, but must avoid specific foods and \\
7 & Total oral intake with no restrictions \\
\hline
\end{tabular}

results. The $p$ values less than 0.05 were considered to be significant.

The study was approved by Local Ethical Committee (HU 2014/ 6916).

\section{Results}

Twenty-three children with a mean age of 5.08 \pm 3.7 years were included. Female male ratio was $15: 8.78 \%$ of patients had neurological impairment. Recurrent respiratory infections (RTI) (n: 14, 60.8\%), swallowing dysfunction (n:13, 56.5\%) and vomiting (n:10, 43.4\%) were the most common symptoms (Table IV). More than two symptoms was existing in 47\% (n:11) of patients. Preoperatively GER was diagnosed with BSS (n:20, 87\%) and with $\mathrm{pH}$ metry (n:8, 34.8\%). In $39.1 \%$ of patients, medical treatment for GER was used with a mean duration of $8 \pm 5.8$ months. Indications for NF were listed in Table IV. Postoperative UGI studies and $\mathrm{pH}$ metry showed no GER after NF in $95 \%$ of patients. No distal esophageal narrowing was detected at postoperative UGI series. Number of RTI were significantly decreased after NF (preoperative vs postoperative infection rate per year was 4.21 vs 1.6 respectively, $\mathrm{p}<0.05)$. Comparison of VFS, PAS and FOIS are also listed in Table V.

Table IV. Demographic Features of Patients $(n=23)$.

\begin{tabular}{ll}
\hline Features & Results \\
\hline Age (year) & $5.08 \pm 3.7$ \\
Gender (Female : Male) & $15: 8$ \\
Symptoms n (\%) & $14(60.8 \%)$ \\
Recurrent respiratory infection Swallowing & $13(56.4 \%)$ \\
Vomiting & $10(43.4 \%)$ \\
Preoperative GER diagnosis Upper GI contrast graphy & $20(87 \%)$ \\
pH metry & $8(34.8 \%)$ \\
Patients that received medical treatment for GER, n (\%) & $9(39.1 \%)$ \\
Duration of medical treatment (month) & $8 \pm 5.7 *$ \\
Indications of NF; n (\%) & \\
$\quad$ Swallowing dysfunction with GER & $18(78 \%)$ \\
GER complications & $6(26 \%)$ \\
Associated anatomical problems & $4(17.3 \%)$ \\
Pnresponsiveness to medical treatment & $3(13 \%)$ \\
Postoperative GER, n (\%) & $5 \%$ \\
\hline
\end{tabular}

*Mean and standard deviation GER: gastroesophageal reflux, NF: Nissen fundoplication 
Table V. Comparison of Preoperative and Postoperative VFS, PAS and FOIS.

\begin{tabular}{lclc}
\hline Parameter & $\begin{array}{l}\text { Preoperative } \\
\text { (median levels) }\end{array}$ & $\begin{array}{l}\text { Postoperative } \\
\text { (median levels) }\end{array}$ & $\mathrm{p}$ values \\
\hline VFS & $0(0-3$ & $0(0-3$ & $\mathrm{p}=0.02^{*}$ \\
UES opening & $2(0-2)$ & $1(0-3)$ & $>0.05$ \\
Esophageal clearance & $1(0-1)$ & $1(0-1)$ & $>0.05$ \\
Motility problem & $1(0-1)$ & $1(0-1)$ & $>0.05$ \\
$\begin{array}{l}\text { Esophago- } \\
\text { pharyngeal back-flow }\end{array}$ & $0(0-1)$ & $0(0-1)$ & $>0.05$ \\
LES narrowing & & & $\mathrm{p}=0.01^{*}$ \\
PAS & $8(1-8)$ & $1(1-8)$ & $\mathrm{p}=0.015^{*}$ \\
PAS for liquids & $5(1-8)$ & $1(1-8)$ & $\mathrm{p}=0.03^{*}$ \\
PAS for semi-liquids & $1(1-7)$ & $3(1-7)$ & $\mathrm{p}=0.01^{*}$ \\
FOIS & $4(0-12)$ & $1(0-6)$ & \\
FOIS & &
\end{tabular}

$\left({ }^{*} \mathrm{p}<0.05\right)$.

VFS: videofluoroscopy, PAS: penetration aspiration, FOIS: functional oral intake scales, UES: upper esophageal sphincter, RTI: respiratory tract infection

Although esophageal motility parameters such as esophageal cleaning, esophageal peristalsis, esophageal backflow and lower esophageal sphincter narrowing did not alter after NF ( $\mathrm{p}>0.05$ ), upper esophageal opening (UEO) was significantly decreased when compared to preoperative VFS findings $(\mathrm{p}<0.05)$.

Figure 1 shows aspiration of liquids in preoperative VFS and improved after NF.

\section{Discussion}

Postoperative dysphagia (PD) is a common complication after antireflux surgery and has been reported with an incidence of $24 \%$ in pediatric population ${ }^{6}$. Most of the symptoms occur in the first 6 weeks after surgery and usually subsides within few weeks. Temporary dysphagia may be attributable to esophageal edema, stretching or temporary hypomotility? PD persists in only $7 \%$ of patients beyond a year after $\mathrm{NF}^{8}$. Severe PD are mainly related with anatomical problems including tight, twisted or slipped fundoplication, paraesophageal herniation and hiatal stenosis ${ }^{1}$.

When patients with an esophageal stricture are excluded, preoperative dysphagia occurs in $20-50 \%$ of cases before antireflux surgery and may improve after fundoplication. However, it has been reported that preoperative dysphagia worsened in $2-14 \%$ of cases ${ }^{9-10}$. Preoperative motility studies including $\mathrm{pH}$ metry, esophageal impedance and manometry was performed to predict postoperative improvement and complications after NF in children. However, no objective method has been defined to identify who are more likely to respond well to NF and no diagnostic tool has been found effective to predict PD preoperatively. Based on $\mathrm{pH}$-impedance studies, the mean number of GER episodes, acid exposure, and impedance baseline values were significantly reduced after surgery ${ }^{11}$. However, none of them were able to predict occurrence of PD after surgery. In adults, esophageal manometry findings such as preoperative decreased lower esophageal sphincter (LES) resting pressures, residual LES relaxation, intrabolus pressures and distal peristaltic amplitudes are considered as poor predictors of $\mathrm{PD}^{12,13}$. Recently, Myers et al. ${ }^{3}$ introduced automated impedance manometry (AIM) which integrates pressure and impedance measurements and developed dysphagia risk index which is highly sensitive to predict new-onset dysphagia after antireflux surgery ${ }^{3}$. Although AIM is a highly sensitive method, it requires manometric intervention and patient consistence. VFS is a dynamic method investigating all phases of swallowing in children. It also gives an idea about aspiration and bolus passage of food along the esophageal body during the examination. In order to evaluate the effect of NF on deglutitive functions, we performed VFS 
before and after NF and compare the results of patients. Since, results of motility studies are variable and rarely reliable in children, VFS evaluation enables to evaluate the physiologic swallowing function.

In our study, half of our patients had swallowing problems prior to NF and $78 \%$ had neurologic impairment. Esophageal motility parameters such as esophageal cleaning, esophageal peristalsis, esophageal backflow and lower esophageal sphincter narrowing did not alter after NF in our patients. Postoperative upper GI studies also confirmed that there was no distal esophageal narrowing due to tight wrap. The only VFS finding which showed significant difference after NF was UEO. The mean UEO scores were significantly decreased after NF. These results suggest that upper esophageal sphincter opening is better after NF and there is less food retention in the proximal esophagus. Although, the mechanism of this finding is unclear, we speculate that better esophageal bolus passage in the proximal esophagus can be explained by decreased reflux episodes. Less food retention in the upper esophageal sphincter may also suggest less airway penetration and aspiration in children after NF. Baigrie et al. ${ }^{14}$ reported a prospective study and found that incidence of dysphagia was not increased in patients with preoperative esophageal hypomotility. Although preoperative esophageal hypomotility was not evaluated in this study, we suggest that better VFS results after NF can be attributed to possible motility problems in our group of patients with neurologic problems.

RTI is a common complication of GERD in children with neurologic impairment and considered as an indication for antireflux surgery. Retrospective studies demonstrate that fundoplication is responsible for relief in respiratory symptoms in $45 \%$ of patients ${ }^{15}$. In our series of patients the mean frequency of RTI was 4/year before NF and decreased to one per year after fundoplication. Also, PAS were significantly decreased after NF both for liquids and semi-liquids. Since 95\% of patients did no show GER findings in postoperative UGI and 24-hour $\mathrm{pH}$ studies, we suggest that decreased penetration and aspiration can be explained by decreased reflux episodes. It has been suggested that NF is more effective for resolution of digestive symptoms than respiratory functions ${ }^{15}$. Decreased risk of aspiration may be responsible for better respiratory functions after fundoplication.

Improvement in functional oral intake is an important goal for neurologically impaired children. Children needing feeding gastrostomy may also require NF for underlying GERD or possible GER development after gastrostomy. FOIS is used to document functional oral food intake in children. The mean FOIS in our patients significantly improved after NF. Patients with swallowing dysfunction before NF had better results than patients who underwent NF for other indications. Although, none of the previous studies including our results confirmed better esophageal motility after NF, functional feeding capabilities of children may improve after anti-reflux surgery.

Although, we have limited number of patients and evaluate the results of both normal and neurologically impaired children, our results suggest that penetration and aspiration were significantly decreased after NF and children had less RTI. Better deglutitive functions after NF can be explained by decreased GER episodes in children. Though, esophageal motility evaluated by VFS did not changed after anti-reflux surgery, functional oral intake significantly improved in patients especially with swallowing dysfunction. We suggest that PD may be a problem of children with normal deglutitive functions prior surgery.

\section{REFERENCES}

1. Wills VL, Hunt DR. Dysphagia after antireflux surgery. Br J Surg 2001; 88: 486-499.

2. Loots C, van Herwaarden MY, Benniniga MA, et al. Gastroesophageal reflux, esophageal function, gastric emptying, and the relationship to dysphagia before and after anti-reflux surgery in children. J Pediatr 2013; 162: 566-573.

3. Myers JC, Nguyen NQ, Jamieson GG, et al. Susceptibility to dysphagia after fundoplication revealed by novel automated impedance manometry analysis. Neurogastroenterol Motil 2012; 24: 812-e393.

4. Yalcin S, Demir N, Serel S, Soyer T, Tanyel FC. The evaluation of deglutition with videofluroscopy after repair of esophageal atresia and/or tracheoesophageal fistula. J Pediatr Surg 2015; 50: 1823-1827.

5. Crary MA, Mann GD, Groher ME. Initial psychometric assessment of a functional oral intake scale for dysphagia in stroke patients. Arch Phys Med Rehabil 2005; 86: 1516-1520. 
6. Kubiak R, Andews J, Grant HW. Long term outcome of laparoscopic Nissen fundoplication campared with laparoscopic thal fundoplication in children: a prospective, randomized study. Ann Surg 2011; 253: 44-49.

7. Myers JC, Jamieson GG, Wayman J, King DR, Watson DI. Esophageal ileus following laparoscopic fundoplication. Dis Esophagus 2007; 20: 420-427.

8. Karim SS, Panton ON, Finley RJ, et al. Comparison of total versus partial laparoscopic fundoplication in the management of gastroesophageal reflux disease. Am J Surg 1997; 173:375-378.

9. Wetscher GJ, Glaser K, Gadenstaetter M, Profanter C, Hinder RA. The effect of medical therapy and antireflux surgery on dysphagia in patients with gastroesophageal reflux disease without esophageal stricture. Am J Surg 1999; 177:189-192.

10. Franzen T, Boström J, Tibbling Grahn L, Johanson K. Prospective study of symptoms and gastroesophageal reflux 10 years after posterior partial fundoplication. Br J Surg 1999; 86: 956-960.
11. Smits MJ, Loots CM, Benninga MA, Omari TI, Wijk MP. New insights in gastroesophgaeal reflux, esophageal function and gastric emptying in relation to dysphagia before and after anti-reflux surgery in children. Curr Gastroenterol Rep 2013; 15: 351.

12. Cole SJ, van den Bogaerde JB, van der Walt $H$ Preoperative esophageal manometry does not predict postoperative dysphagia following anti-reflux surgery. Dis Esophagus 2005; 18: 51-56.

13. Scheffer RC, Samsom M, Frakking TG, et al. Long-term effect of fundoplication on motility of the esophagus and oesphagogastric junction. Br J Surg 2004; 91: 1466-1472.

14. Baigrie RJ, Watson DI, Myers JC, Jamieson GG. Outcome of laparoscopic Nissen fundoplication in patients with disordered preoperative peristalsis. Gut 1997; 40: 381-385.

15. Tannuri ACA, Tannuri U, Mathias AL, Velhote CP, Romao RLP, Gonçalves MEP. Gastroesophgaeal reflux disease in children: efficacy of Nissen fundoplication in treating digestive and respiratory symptoms. Experience of a single center. Dis Esophagus 2008; 21: 746-750. 